\title{
Study on Two-Phase Flow and Temperature Characteristics of Direct Methanol Fuel Cells
}

\author{
Hongrong Xia \\ Key Laboratory of Surface Functional Structure \\ Manufacturing of Guangdong Higher Education \\ Institutes \\ South China University of Technology \\ Guangzhou, China \\ xiahr_scut@163.com
}

Wei Yuan*

Key Laboratory of Surface Functional Structure

Manufacturing of Guangdong Higher Education Institutes

South China University of Technology

Guangzhou, China

mewyuan@scut.edu.cn

\author{
Zhaochun Zhang \\ Key Laboratory of Surface Functional Structure \\ Manufacturing of Guangdong Higher Education \\ Institutes \\ South China University of Technology \\ Guangzhou, China \\ 985467137@qq.com \\ Aoyu Wang \\ Key Laboratory of Surface Functional Structure \\ Manufacturing of Guangdong Higher Education \\ Institutes \\ South China University of Technology \\ Guangzhou, China \\ 308460867@qq.com
}

\begin{abstract}
Visualization study of two-phase flow in serpentine anode flow field of a liquid-feed direct methanol fuel cell (DMFC) was performed, and also the internal temperature characteristics of the flow in the DMFC have been studied in order to investigate the effect of important operating parameters. The results show that the two-phase flow behavior in the serpentine anode flow field with different flow rate of methanol solution is similar to each other. It was a similar periodical repetition of a process of bubble formation, detachment and coalescence to gas slug in the serpentine flow field. The flow rate of methanol solution can influence the mass transport of methanol and the internal temperature in the flow channel. On one hand, an increase in flow rate will lead to an increase in the gas bubble removal rate, which can increase the fuel cell performance. On the other hand, the increased flow rate of methanol solution will also take more heat of reaction away and reduce the temperature in the flow channel, which will degrade the fuel cell performance.
\end{abstract}

Keywords- DMFC; two-phase flow; serpentine channel; temperature characteristics; visualization

\section{INTRODUCTION}

As a device that converts chemical energy into electrical energy, fuel cell has the advantages of high efficiency and environmental friendly and has been widely concerned. Liquid feed Direct Methanol Fuel Cell (DMFC) is one of the proton exchange membrane Fuel Cell, due to its unique advantages, such as higher energy densities, facile liquid fuel storage, and simpler system structures, the DMFC has been identified as one of the most promising power sources for portable and mobile applications [1-4].

On the anode, methanol solution is supplied through the anode flow field to the anode catalyst layer, where part of methanol is oxidized to generate electrons, protons, and
$\mathrm{CO}_{2}$. On the cathode, oxygen/air is supplied through the cathode flow field and transfers through the cathode diffusion layer to the cathode catalyst layer, where major part of oxygen reacts with the protons that are conducted through the membrane from the anode and the electrons that come from the external circuit to form water. Clearly, there are two-phase flows on both the anode and the cathode in the liquid feed DMFC, which can both significantly affect cell performance. So the study on gas $\mathrm{CO}_{2}$ management at the anode and liquid water management at the cathode is of great significance. Several studies on the two-phase flow patterns in the anode flow field have been reported recently. Argyropoulos et al. [5] studied the $\mathrm{CO}_{2}$ bubble flow characteristics in a DMFC based on two different parallel flow channels. It was observed that there were three two-phase flow patterns, including bubbly, slug and annular flow according to different levels of gas fraction, and gas slug clogging often occurred in some of the flow channels of the parallel flow fields. Yang et al. [2] studied the $\mathrm{CO}_{2}$ bubble behavior in the anode flow field of an in-house fabricated transparent DMFC. The effects of cell orientations, methanol solution flow rates, and operation temperatures were investigated. Wong et al. [6] visually studied an in-house fabricated micro DMFC with various-sized micro single serpentine channels down to $400.0 \mu \mathrm{m}$ and demonstrated that the $\mathrm{CO}_{2}$ bubble behavior depended on the channel width. The study of mass transport in the anode has mainly been focused on flow field geometry, the flow field design and the operating conditions [5-12]. However, there are few combination of research on two-phase flow and its temperature characteristics.

In this paper, we designed a DMFC single cell based on serpentine flow field. We present a visual investigation of $\mathrm{CO}_{2}$ gas bubble behavior in a transparent DMFC with its anode flow. Effects of methanol solution flow rate on 
the cell performance, the two-phase flow characteristics and the temperature characteristics anode flow field were examined.

\section{EXPERIMENT}

\section{A. Transparent DMFC}

A transparent DMFC was designed and fabricated for this visualization study, as schematically shown in Fig. 1. The membrane electrode assembly (MEA) detailed in the subsequent paragraph, was sandwiched between two bipolar plates with a gasket onto either side of the MEA. This assembly, including the bipolar plates and MEA, was clamped between two enclosure plates by eight M4 screw joints. To avoid corrosion, the flow field plates were made of 316 stainless steel plates with a thickness of $1.5 \mathrm{~mm}$. It was machined by the wire-cut technology. The width of the ribs was $1.2 \mathrm{~mm}$. The serpentine channels have a total length of $390 \mathrm{~mm}$ and the width of the channels was 1.5 $\mathrm{mm}$. For the purpose of visualization, the two enclosure plates, each having a thickness of $15 \mathrm{~mm}$, were made of organic glass plate.

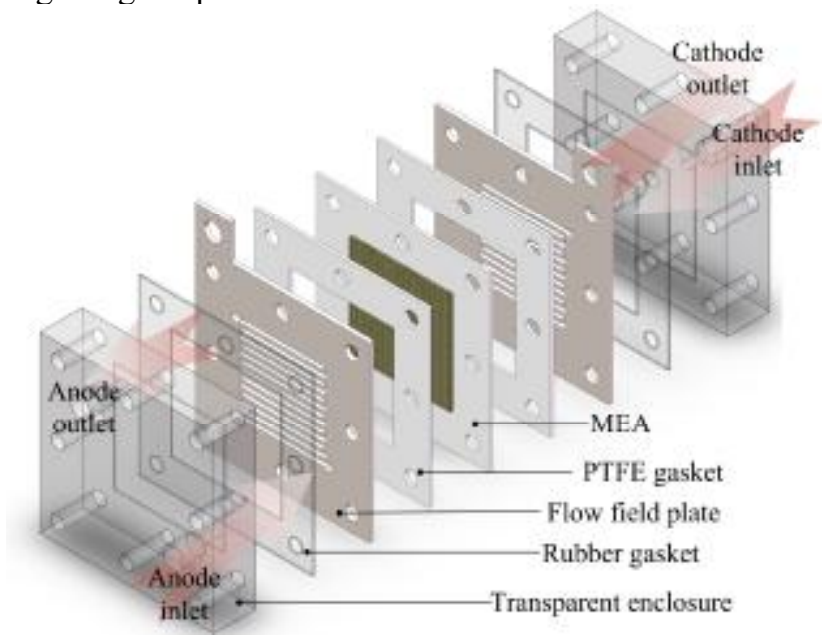

Figure 1. Schematic of the transparent DMFC.

The MEA, fabricated in this work, had an active area of $3.0 \times 3.0 \mathrm{~cm}^{2}$ and consisted of two single-side electrodes and a Nafion ${ }^{\circledR}$ membrane 117 . Both anode and cathode electrodes used carbon paper TGP-H-060 as the backing support layer with 20\% PTFE wet-proofing treatment. The catalyst loadings were prescribed with $4 \mathrm{mg} \mathrm{cm}^{-2} \mathrm{Pt}-\mathrm{Ru}$ $(1: 1, \mathrm{a} / \mathrm{o})$ at the anode and $2 \mathrm{mg} \mathrm{cm}^{-2} \mathrm{Pt}$ at the cathode, respectively. The Nafion ${ }^{\circledR}$ membrane 117 , before being used, was first cleaned following a standard procedure: it was pretreated following the processes below: At the beginning, the membrane was boiled in 3 wt. $\% \mathrm{H}_{2} \mathrm{O}_{2}$ aqueous solution for 1 hour and then in de-ionized (DI) water for 1 hour. Then, it was boiled in $0.5 \mathrm{M} \mathrm{H}_{2} \mathrm{SO}_{4}$ aqueous solution for 1 hour. Finally, it was purified again in boiling DI water to remove the residual sulfuric acid.

\section{B. Test loop and conditions}

The experiments were carried out in the test loop shown in Fig. 2. A commercial electronic load was used to test the fuel cell discharge performance, and a LabVIEWbased data acquisition (DAQ) program was used to record the current and voltage outputs. Methanol solution was driven by a digital micro-pump. Simultaneously, high purity oxygen of $99.99 \%$ as oxidant was provided to the cathode side of the cell without humidification. The flow rate of oxygen was controlled and measured by a mass flow meter. A video and photo imaging system, including a digital camera (Panasonic DMC-ZS10), was employed to capture the images of the two-phase flow characteristics of gas $\mathrm{CO}_{2}$ and methanol solution in the anode flow field. Furthermore, a temperature acquisition system (ADAM4018 and ADAM-4520) interfaced to a computer was employed to gather the temperature of two-phase flow in in the anode flow field, which have seven temperature acquisition points as shown in Fig. 2.

Methanol solution entered into the anode flow field from the lower left corner, while oxygen gas was fed into the cathode flow field from the upper right corner. In such a flow configuration, it would be able to avoid the accumulation of produced gas $\mathrm{CO}_{2}$ in the anode flow channel and of liquid water in the cathode flow channel. Furthermore, all the experiments were performed under the same condition: a constant methanol solution concentration of $2 \mathrm{M}$ and a constant oxygen gas flow rate of 100 Standard Cubic Centimeter per Minute (SCCM). Over the experiment, the fuel cells were tested at an ambient pressure and a room temperature of approximately $25{ }^{\circ} \mathrm{C}$.

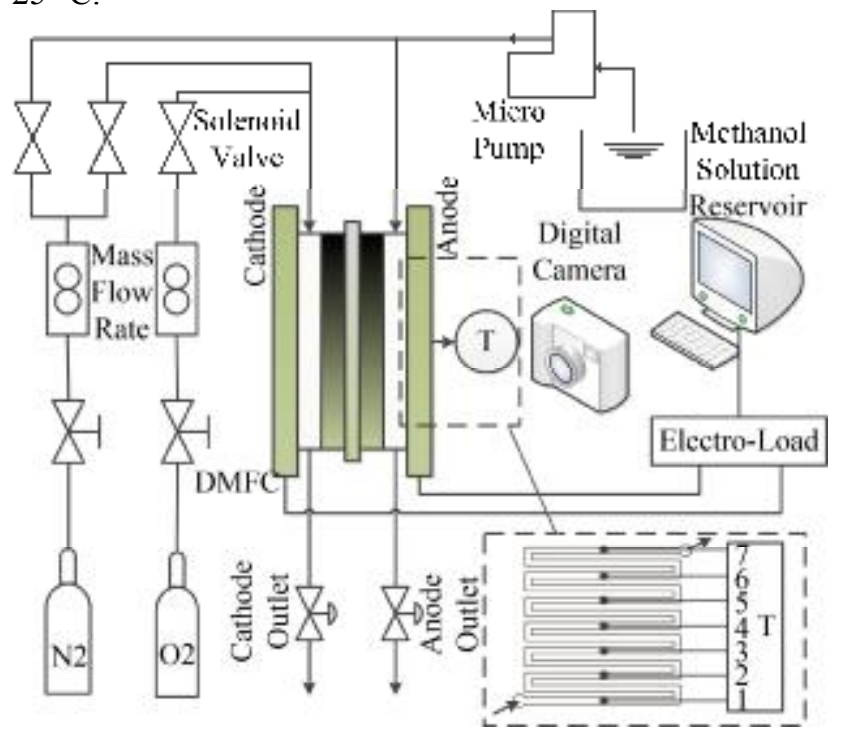

Figure 2. Schematic of the DMFC test loop.

\section{RESULT AND DISCUSSION}

\section{A. Two-phase flow characteristics in the anode flow field}

Through visualization study, it was found that the twophase flow showed different characteristics with the current density changes. Now take the methanol flow rate of $2 \mathrm{ml} \mathrm{min}^{-1}$ for example. Fig. 3 shows the representative images of the $\mathrm{CO}_{2}$ gas bubble behavior with different current density. As can be observed from the images for Fig. 3 (a) corresponding to small current densities of 20 $\mathrm{mA} \mathrm{cm}{ }^{-2}$, a rather small number of discrete gas $\mathrm{CO}_{2}$ bubbles were generated and presented in the flow field. With the increase of current density, the small bubbles were growing larger slowly, then entered in the solution and swallowed the next bubble to form a slug flow (Fig. 3 
(b)), it may form multiple slug flow during this period, and the methanol slug flow will merge into a big slug flow if the flow rate is too low. A new round cycle of bubble forming to slug flow and then discharge started is shown in Fig. 3 (c). The characteristic of two-phase flow at high current density is similar to that in low current density, which is shown in Fig. 3 (d), but the flow field may be predominated by rather long gas slugs, which led to a determination in the cell performance. The $\mathrm{CO}_{2}$ gas bubble behavior of different methanol solution flow rates was similar to each other. However, for lower methanol solution flow rates below $1 \mathrm{ml} \mathrm{min}^{-1}$, some long gas slugs were present in the flow field, which reduced the effective contact area between methanol and the gas diffusion layer and, thus led to poor cell performance. On the contrary, an increase in the methanol solution flow rate will reduce the average size and the number of gas slugs in the flow field, thereby enhancing the methanol mass transfer.

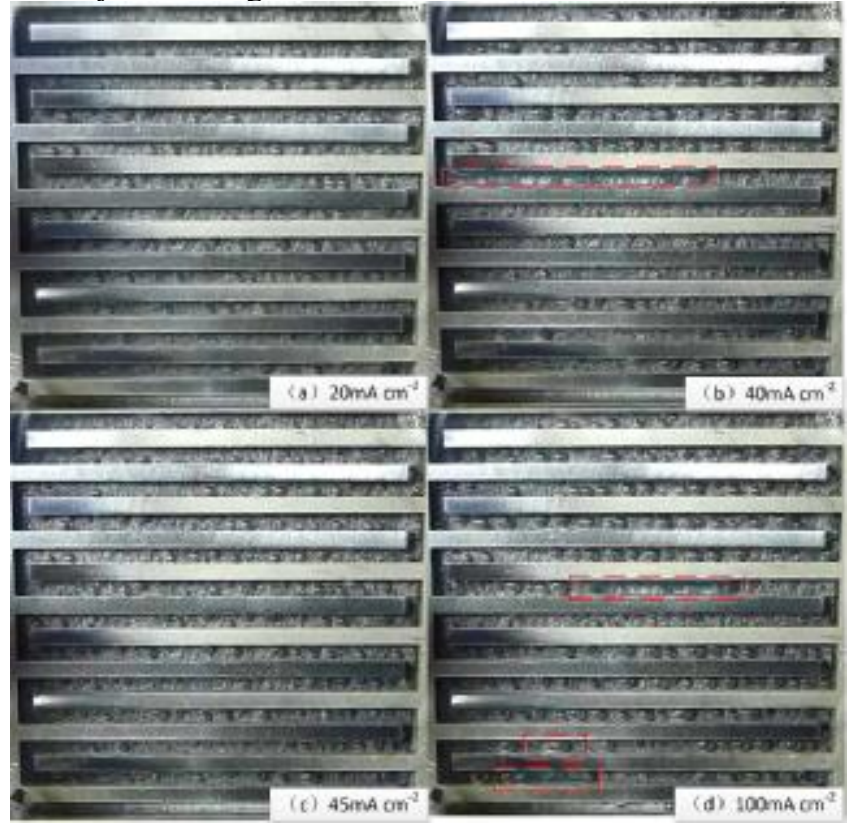

Figure 3. $\quad \mathrm{CO}_{2}$ bubble behavior at different current densities $(2.0 \mathrm{ml}$ $\left.\min ^{-1}\right)$.

\section{B. Temperature characteristics in the anode flow field}

As seen from Fig. 4, an increase in the methanol solution flow rate from 0.5 to $1.0 \mathrm{ml} \mathrm{min}^{-1}$ led to the improved cell performance. However, the cell performance became worse as the flow rate was further increased from 1.0 to $4.0 \mathrm{ml} \mathrm{min}{ }^{-1}$. This can be explained by the temperature characteristics in the anode flow field as shown in Fig. 5(a-d), corresponding, respectively, to the methanol flow rates of $0.5,1.0,2.0$, and $4.0 \mathrm{ml} \mathrm{min}^{-1}$. It indicates that the temperatures of all the seven channels in the flow field were gradually reduced with increasing the methanol solution flow rate from 0.5 to $4.0 \mathrm{ml} \mathrm{min}^{-1}$. Furthermore, the flow channel with the highest temperature changed from channel 4,5 to channel 6,7 with the increase of the methanol solution flow rate. It demonstrated that the increased flow rate of methanol solution take more heat of reaction away and reduce the temperature in the flow channel. For low temperature liquid DMFC, the effect of temperature on the activity of the catalyst is very sharp and cannot be ignored. The lower temperature led to a lower activity of the catalyst. As a result, the cell performance became worse and worse when the methanol solution flow rate was increased from 1.0 to $4.0 \mathrm{ml} \mathrm{min}$. So the selection of flow rate of methanol solution should be comprehensive consideration of $\mathrm{CO}_{2}$ emissions and the influence of temperature on the anodic catalytic reaction, to ensure the DMFC to achieve optimal performance.

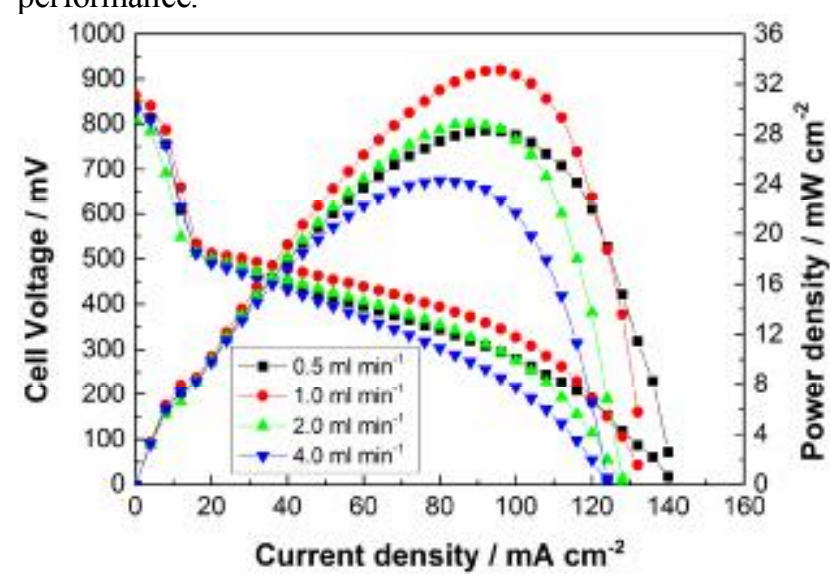

Figure 4. Effects of the methanol solution flow rate on the cell performance.
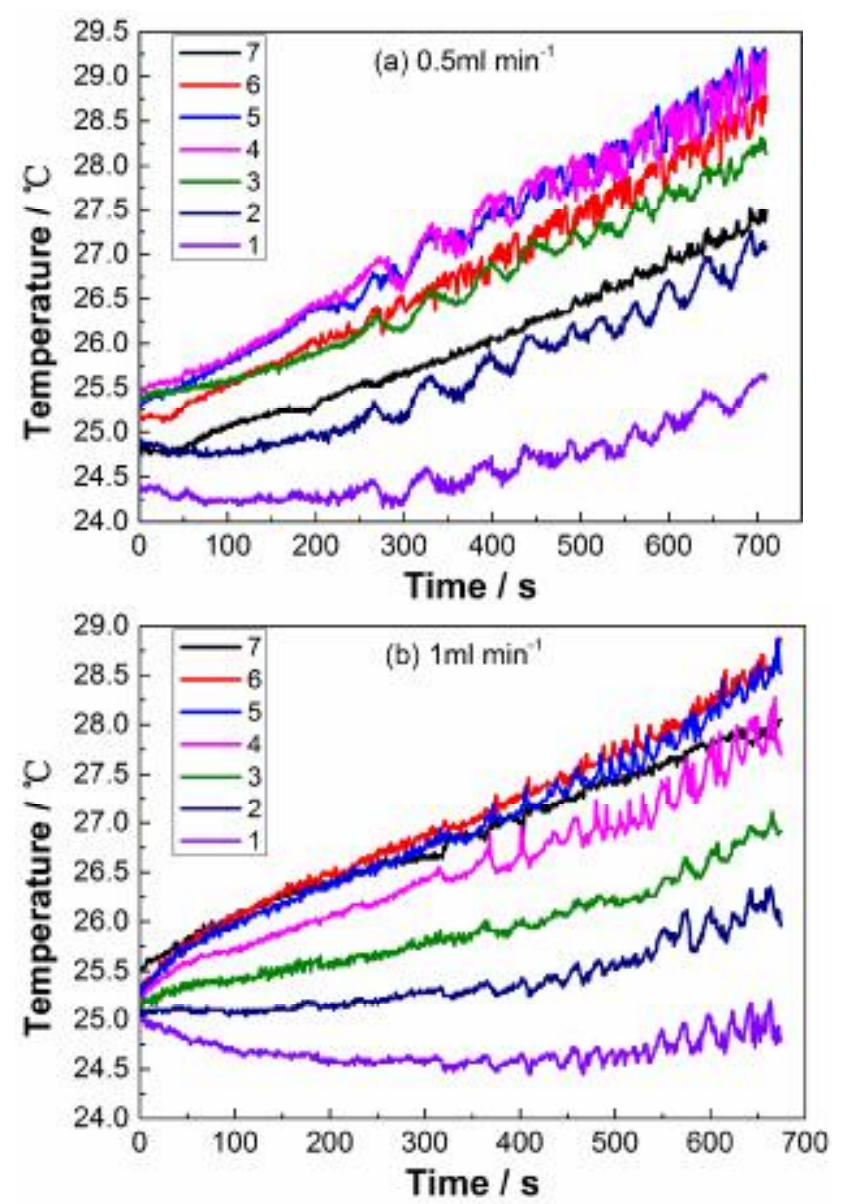

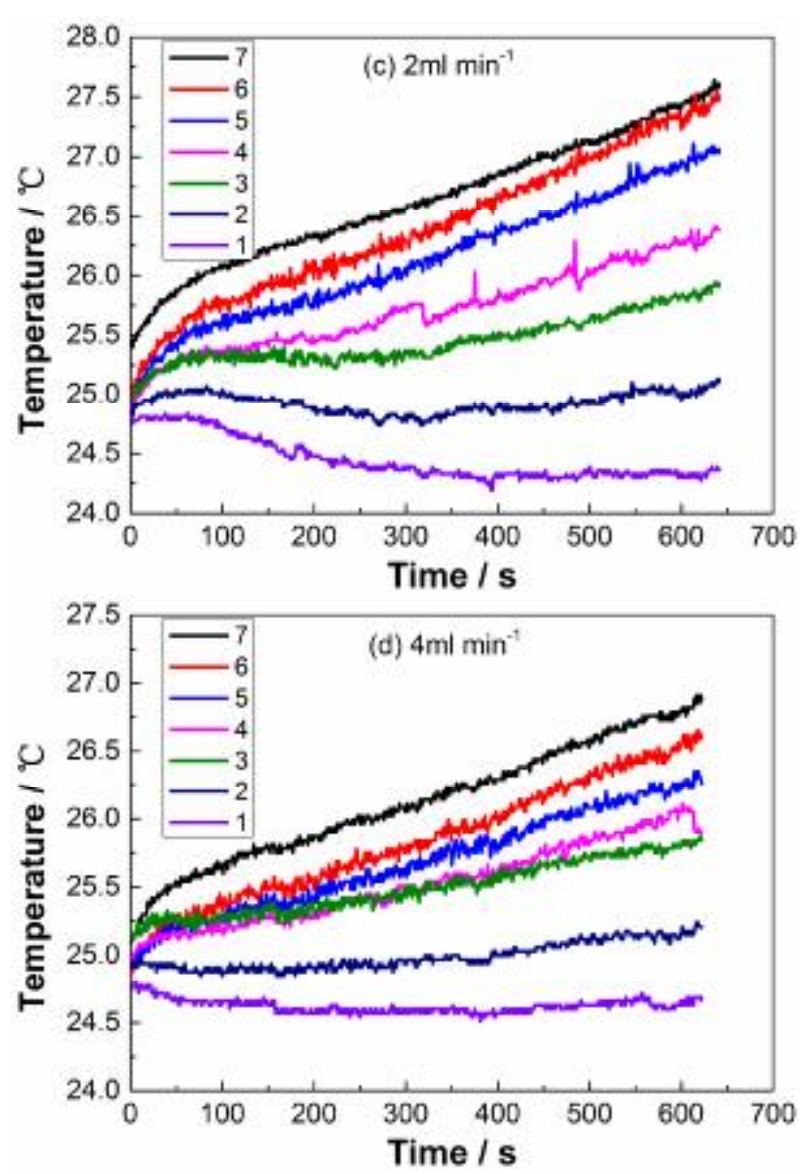

Figure 5. Effects of the methanol solution flow rate on the temperature of each flow channels.

\section{CONCLUSIONS}

In the present work, a visual investigation of $\mathrm{CO}_{2}$ gas bubble behavior inside the anode flow field consisting of a single serpentine channel has been performed. A set of experiments are presented in order to evaluate the effect of the methanol solution flow rate. Based on the results and discussion, the conclusions can be made point by point as follows:

i) The two-phase flow behavior in the serpentine anode flow field with different flow rate of methanol solution is similar to each other. At low current densities, a rather small number of discrete gas $\mathrm{CO}_{2}$ bubbles were generated and presented in the flow field. With the increase of current density, the small bubbles were growing larger slowly, then entered in the solution and swallowed the next bubble to form a slug flow. And at high current densities, the flow field was predominated by rather long gas slugs, which led to a determination in the cell performance. ii) The flow rate of methanol solution can not only influence the mass transport of methanol, but also influence the internal temperature in the flow channel. On one hand, an increase in flow rate will lead to an increase in the gas bubble removal rate, which can increase the fuel cell performance. On the other hand, however, the increased flow rate of methanol solution will also take more heat of reaction away and reduce the temperature in the flow channel, which will degrade the fuel cell performance.

\section{ACKNOWLEDGMENT}

This work is financially supported by the National Natural Science Foundation of China (Grant No. 51475172)and the Natural Science Foundation of Guangdong Province (Grant No. S2013040016899).

\section{REFERENCES}

[1] Larminie, James, Andrew Dicks, and Maurice S. McDonald. Fuel cell systems explained. Vol. 2. New York: Wiley, 2003.

[2] Yang, H., T. S. Zhao, and Q. Ye. "In situ visualization study of CO 2 gas bubble behavior in DMFC anode flow fields." Journal of Power Sources 139.1 (2005): 79-90.

[3] Yuan, Zhenyu, et al. "Hydrophilicity effect on micro-scale flow of DMMC." Microelectronic Engineering (2014):131-136.

[4] Xu, C., et al. "Analysis of Mass Transport of Methanol at the Anode of a Direct Methanol Fuel Cell." Journal of The Electrochemical Society153.7(2005).

[5] P. Argyropoulos, K. Scott and W.M. Taama, "Carbon dioxide evolution patterns in direct methanol fuel cells." Electrochimica Acta, 44, 3575 (1999).

[6] Wong CW, Zhao TS, Ye Q, Liu JG. "Transient capillary blocking in the flow field of a micro-DMFC and its effect on cell performance." Journal of The Electrochemical Society, 2005;152:A1600-5.

[7] J. C. Amphlett, B. A. Peppley, E. Halliop and A. Sadiq, "The effect of anode flow characteristics and temperature on the performance of a direct methanol fuel cell." Journal of Power Sources, 96, 204 (2001).

[8] C.W. Wong, T.S. Zhao, Q. Ye and J.G. Liu, "Experimental investigations of the anode flow field of a micro direct methanol fuel cell." Journal of Power Sources, 155, 291 (2005).

[9] A. Kumar and R. G. Reddy, "Effect ofchannel dimensions and shape in the flow-field distributor on the performance of polymer electrolyte membrane fuel cells." Journal of Power Sources, 113, 11 (2003).

[10] Y. G. Yoon, W. Y. Lee, G. G. Park, T. H.Yang and C. S. Kim, "Effects of channel configurations of flow field plates on the performance of a PEMFC." Electrochimica Acta, 50, 709 (2004).

[11] J. Scholta, F. Häussler, W. Zhang, L.Kuppers, L. Jörissen, W. Lehnert, "Development of a stack having an optimized flow field structure with low cross transport effects." Journal of Power Sources, 155, 60 (2006).

[12] Biswas, M.A.R., et al. "Systematic approach for modeling methanol mass transport on the anode side of direct methanol fuel cells."International Journal of Hydrogen Energy 39.15(2014):8009-8025. 